Revista de Comunicación y Salud, 2020, Vol. 10, oㅡ 2, pp. 385-396

Editado por Cátedra de Comunicación y Salud

ISSN: 2173-1675

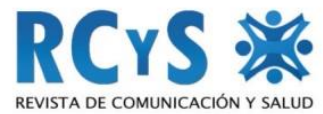

Enviado $15 / 08 / 2020$

Aprobado 09/09/2020

\title{
LA PRENSA DIGITAL EN TIEMPOS DE LA COVID-19: ANÁLISIS LINGÜÍSTICO DE LOS TITULARES PUBLICADOS EN ÁVILARED
}

\section{Online Press during COVID-19: Linguistic Analysis of Headlines published on Ávilared}

Carmen Vanesa Álvarez-Rosa ${ }^{1}$

Universidad de Salamanca. España.

vane@usal.es

Ángel Manuel Romero López

Sanidad de Castilla y León (Sacyl). España.

amromero@saludcastillayleon.es

\section{Resumen}

La situación de inestabilidad social y sanitaria advenida por la enfermedad COVID-19 ha supuesto la inclusión obligada de contenidos informativos sobre esta cuestión de salud y sus consecuencias en la prensa. Este trabajo se aproxima a una investigación que desea dar a conocer la codificación lingüística de los titulares de noticias publicados en el principal periódico digital de la ciudad de Ávila (España) —Ávilared-, por el escaso número de trabajos que estudian los titulares de prensa en papel (Zorrilla, 1996; Nadal Palazón, 2012), que son menos aún sobre los que hay en soporte digital. En este sentido, avanzamos con una descripción de las particularidades formales de los titulares digitales, ya que esta "nueva prensa es tan joven que no tiene ni teoría, ni historia, ni manual actualizado de sus innovaciones" (Fogel y Patiño, 2007, p .7). El análisis, basado en un corpus de 90 titulares publicados durante todo el período de estado de alarma en España, atiende a siete elementos formales; a saber, la bimembración, la estructura nominal, el empleo de expresiones numéricas, la impersonalización, el inicio con verbo, la aparición del condicional "de rumor" y la omisión de cualquier categoría gramatical. Se demuestra la divergencia de algunos planteamientos resultantes de análisis de titulares de prensa en papel.

Palabras clave: Análisis lingüístico, Titulares, Salud, Prensa digital, COVID-19, Ávila.

\begin{abstract}
1 Carmen Vanesa Álvarez Rosa: Doctora en Filología Hispánica con mención europea por la Universidad de Salamanca, es especialistas en análisis del discurso en su vertiente oral y en didáctica de la lengua.
\end{abstract}


La prensa digital en tiempos de la COVID-19: análisis lingüístico de los titulares publicados en ÁVILARED

The situation of social and health instability caused by the COVID-19 has been containted on press. This work investigates the linguistic codification of the headlines publishes on the main online newspaper in the city of Ávila (Spain) —Ávilared-. There are few studies interested in the analysis of headlines from the traditional newspaper (Zorrilla, 1996; Nadal Palazón, 2012), there are even fewer on the headlines of the online newspaper. We advance with a description of the formal characteristics of 90 digital headlines: impersonal third person, verb in starting position, quoting conditional, bimembration, ellipsis, nominal structures and numerical expression. The results point to a difference between the linguistic mechanisms used in the online media and the traditional one.

Keywords: Linguistic Analysis, Headlines, Health, Online Newspaper, COVID-19, Ávila.

Cómo citar el artículo

Álvarez-Rosa, C. V. y Romero López, A. M. (2020). La prensa digital en tiempos de la COVID-19: análisis lingüístico de los titulares publicados en ÁVILARED. Revista de Comunicación y Salud, 10

https://doi.org/10.35669/rcys.2020.10(2).385-396

\section{INTRODUCCIÓN}

La Real Academia Española en su diccionario en línea define el término 'titular', en su quinta acepción, como "[c]ada uno de los títulos de una revista, de un periódico, etc., compuesto en tipos de mayor tamaño" (https://dle.rae.es/titular). Cercana es la perspectiva adoptada por Martínez Albertos (1983) cuando lo entiende como un sistema de contenido informativo determinado por los condicionantes paralingüísticos. En un trabajo que pretende analizar estos enunciados periodísticos resulta insuficiente detenernos en su aspecto externo ("compuesto por tipos de mayor tamaño"), y más cuando esta cualidad es propia de la prensa tradicional.

Desde el punto de vista de la lingüística tradicional, la definición de 'titular' también carece de completitud al no tener en cuenta sus rasgos textuales. En esta línea, encontramos la propuesta por Alarcos (1977, p.128) cuando determina que son "los letreros con que se indica o se da a conocer el contenido, objeto o destino de un escrito impreso en los periódicos [y está dotado de los elementos propios de un signo autónomo]".

Es por todos sabidos que un buen titular presenta el resumen de la idea principal del contenido informativo y define la orientación que el medio de publicación le otorga al hecho (Van Dijk, 1990), por lo que conforma una representación del cuerpo de la noticia. Si a esto le sumamos la rutina de lectura en plataformas digitales, en la que solo se les echa un vistazo superficial a los titulares, su redacción influye determinantemente en el interés de los lectores por clickear y pasarse al texto completo. En este sentido, las informaciones recogidas en ellos adquieren una relevancia superior al de la propia 
noticia y, a veces, sacian las necesidades informativas de los lectores (Fundéu, 2012; Francescutti, 2009), ya que "si se ha escrito un texto sublime pero no se encuentra el titular adecuado es como si no se hubiera escrito nada" (Fundéu, 2012, p. 341.).

A pesar de la importancia reseñada (información y creatividad) se encuentran voces que manifiestan aún la falta de estudios de esta parte estructural del género discursivo 'noticia' (Zorrilla, 1996; Nadal Palazón, 2012) a pesar de que se han hecho intentos en el ámbito hispanoamericano (Fernández, 2016; Gallardo-Paúls y Enguix Oliver, 2014; Rebollo, 2008; Ruiz Acosta, 1992; Soria Cáceres, 2017; Zorrilla, 1996). Ahora bien, ¿el mismo interés se ha mostrado por el titular digital? La respuesta, lamentablemente, es menos esperanzadora.

En el presente trabajo proponemos realizar una aproximación a las particularidades lingüísticas que han sido empleadas por los redactores del principal periódico digital de la ciudad abulense, Ávilared, para titular las noticias publicadas durante el período del estado de alarma decretado por el Gobierno español, esto es, desde el 14 de marzo al 21 de junio de 2020. El hecho de que se limite el estudio a este periódico viene dado por dos motivos: el primero, es el único que en origen se creó con formato digital, esto es, no hay un correlato analógico (como sucede con el Diario de Ávila); el segundo, por la creencia generalizada — durante algún tiempo del confinamiento- de que el papel de periódico podía vehicular el coronavirus (lo que la prensa del mundo no tardó en desmentir y la Asociación de Medios de Información, en publicar un informe sobre "Fuentes relativas a la transmisión del COVID-19 a través del papel" https://www.farodevigo.es/media/documentos/2020-12-31 DOC 2020-06$\underline{22} 13 \quad 15 \quad 43$ ami-oms.pdf- $)$.

\section{OBJETIVOS}

El objetivo principal de esta investigación consiste en aproximarnos al análisis lingüístico de los titulares de noticias publicadas en un digital de la ciudad de Ávila durante el estado de alarma decretado por la irrupción del COVID-19.

Los objetivos específicos planteados son:

- Identificar el número de titulares que contienen el término COVID-19 en los titulares.

- Analizar la estructura de los titulares atendiendo a los criterios que se han estudiado en la prensa tradicional, esto es, la bimembración, la omisión de categorías gramaticales, la construcción nominal, la impersonalidad, el inicio verbal, el uso del condicional "de rumor" y el empleo de secuencia numérica, dada la importancia que las cifras han supuesto durante este tiempo.

- Cuantificar los rasgos lingüísticos anteriormente enunciados.

- Determinar si existen rasgos predominantes en los titulares digitales o si mantienen la tendencia de los aparecidos en la prensa en papel. 
La prensa digital en tiempos de la COVID-19: análisis lingüístico de los titulares publicados en ÁVILARED

\section{METODOLOGÍA}

Para desarrollar el análisis de los titulares, se hizo una búsqueda en la hemeroteca digital del periódico con los limitadores de contenido que se contempla en la imagen 1. Seleccionamos todos los titulares que contuviera el término genérico de 'COVID' con indiferencia de la sección del periódico en que se encontrara, pero con limitación temporal (desde cuando se hace efectivo el Real Decreto 463/2020, de 14 de marzo, por el que se declara el estado de alarma para la gestión de la situación de crisis sanitaria ocasionada por el COVID-19 hasta el fin del mismo).

\section{Hemeroteca}

Utiliza el buscador para localizar contenidos de nuestro digital.

\begin{tabular}{|c|c|c|c|c|}
\hline covid & & & Buscar & $\approx$ \\
\hline En Sección & Desde fecha & & Hasta fecha & \\
\hline -- Todas las secciones $\quad \checkmark$ & $14-03-2019$ & 晤 & $21-06-2020$ & 果 \\
\hline
\end{tabular}

Imagen 1. Elementos de búsqueda en la hemeroteca de Ávilared.

Fuente: https://avilared.com/library/26.

Por todo ello, el análisis se basa en un corpus de 90 titulares aparecidos en ocho de las diez secciones que el periódico contempla (Ávila, Provincia, Sociedad, Casos, Economía, Ocio y cultura, Deporte, CyL, Miradas, Vídeos), con un único corte temporal, el comprendido entre la puesta efectiva del estado de alarma hasta el fin del misma, esto es, desde el 14 de marzo de 2020 hasta el 21 de junio del mismo año. De manera concreta, los enunciados de nuestro interés se distribuyen de la siguiente manera: una aparición sobresaliente de titulares que contiene la palabra COVID en la sección de "Sociedad" (55) es seguida muy de lejos con noticias sobre el coronavirus en "Provincia" (19) y se reservan con menos de diez concurrencias en el resto de las secciones. Se observa mejor en el gráfico 1. 
La prensa digital en tiempos de la COVID-19: análisis lingüístico de los titulares publicados en ÁVILARED

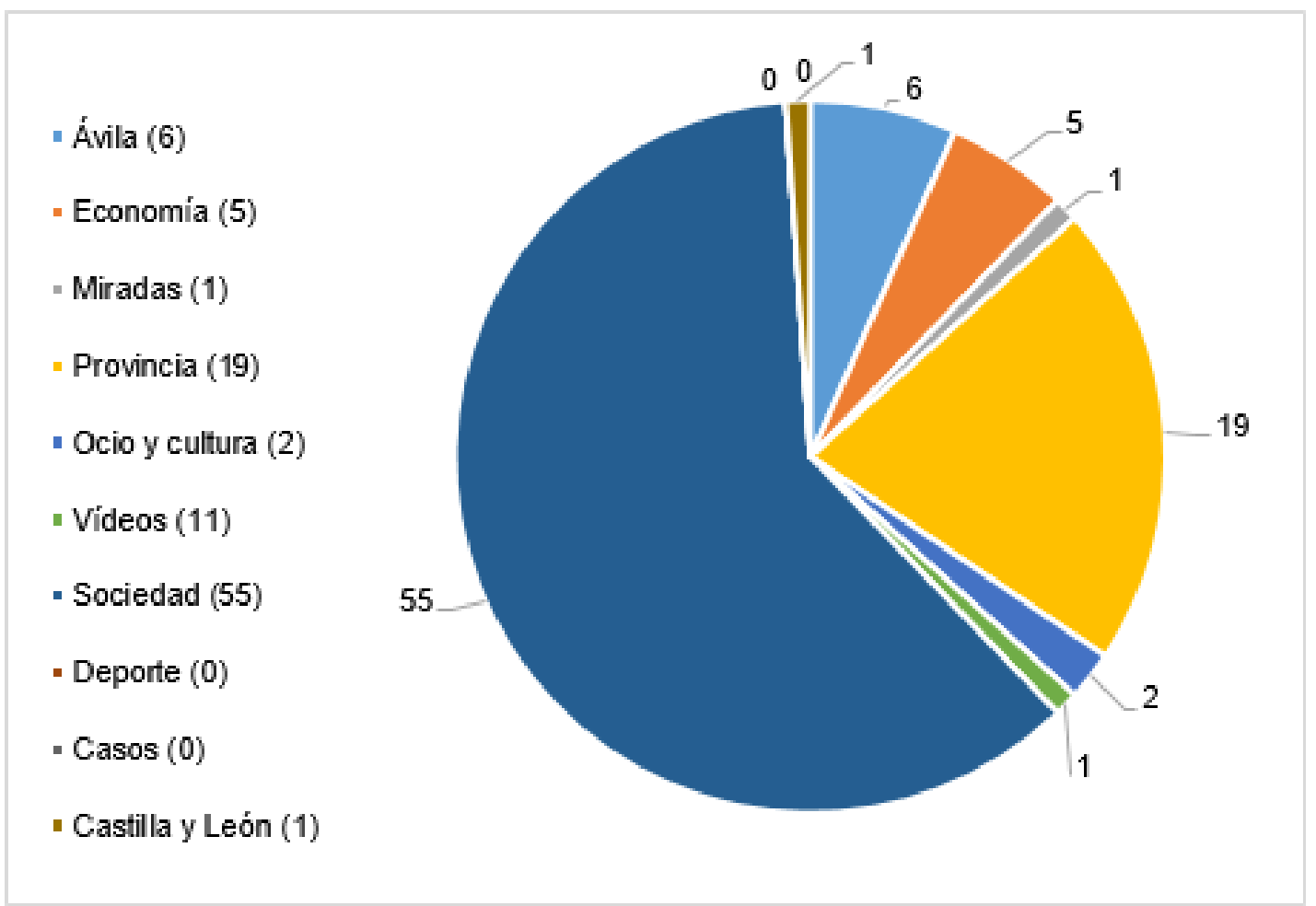

Gráfico 1. Correspondencia de titulares que contienen el término COVID y sección del periódico

Fuente: Elaboración propia.

En términos de porcentajes, se evidencia una distribución lógica de las noticias en las secciones reseñadas. Así, un $61.11 \%$ de titulares que informan sobre la enfermedad de afección pandémica están posicionados en lugares de mayor generalidad, como es "Sociedad (abulense)", y se particularizan en episodios concretos cuando estos especifican el lugar de la noticia; a saber, "Por Ávila y Cs plantean crear un espacio en la capital en recuerdo a los fallecidos por la Covid-19" (TA04². En "Ávila", 24 de mayo de 2020); "El alcalde agradece el esfuerzo de quienes trabajan de forma 'altruista' contra la Covid-19" (TA01. En "Ávila", 21 de abril de 2020); "233 muertes por el Covid19 en la provincia de Ávila" (TP08. En "Provincia", 30 de abril de 2020); "La Adrada aprueba un presupuesto 2020 adaptado a la crisis de la Covid-19" (TP19. En "Provincia", 15 de mayo de 2020); o se destaca alguna actividad relacionada con el ocio y la cultura: "La Banda de la Escuela Municipal de Música rinde homenaje a las víctimas de la Covid-19" (TOyC01. En "Ocio y cultura", 28 de mayo de 2020).

Al considerar los titulares como auténticos textos que permiten ser leídos de manera autónoma e independiente en tanto que expresión concreta de la macroestructura

\footnotetext{
${ }^{2}$ Todos los titulares del corpus se han registrado mediante un código que informa de la sección en la que aparece y el número del titular dentro de la sección. Así, la clave TA04 referencia al titular número 04 de la sección "Ávila". TS referencian los habidos en "Sociedad"; TE, en "Economía"; TP, en "Provincia"; TM, en "Miradas"; TOyC, en "Ocio y cultura"; TV, en "Vídeos"; y TCyL, en "Castilla y León".
} 
La prensa digital en tiempos de la COVID-19: análisis lingüístico de los titulares publicados en ÁVILARED

semántica del relato noticioso (Van Dijk, 1990, p. 77-79), analizamos, por un lado, la codificación lingüística de los rasgos típicos del resumen periodístico inicial, como son la bimembración, la elipsis, las estructuras nominales, la impersonalidad, el uso del verbo en posición inicial del enunciado, el empleo de expresiones numéricas y del condicional "de rumor"; y, por el otro, cuantificamos el empleo de estos mecanismos, con el fin de poder determinar si existen discrepancias entre los rasgos definidores de los titulares tradicionales en papel y los de la prensa digital.

\section{ANÁLISIS}

En este apartado proponemos una aproximación sucinta y sin duda de ningún modo exhaustiva de los mecanismos referidos anteriormente, que son los característicos de los estudios clásicos sobre los titulares periodísticos.

Como ya se ha insinuado, los titulares son textos independientes, producidos en situaciones contextuales concretas, que juegan entre la información, la creatividad y la economía lingüística. Alarcos (1977) apuntaba como rasgo característico de este tipo de enunciados en la prensa en papel la "bimembración expresiva", cuya intención se dirige

bien a contraponer esos dos elementos de la sustancia de la situación que llamamos tema y tesis, bien a desgajar por marginación o por relieve alguno de los elementos constitutivos de la secuencia lingüística completa, bien -en los casos de coordinación - a marcar el contraste entre dos temas o dos tesis conectados con la misma tesis o, respectivamente, con el mismo tema. (Alarcos, 1977, p. 148)

Dicho con otras palabras, con este mecanismo la información consabida y la nueva conforman una estructura segmentada ya por marginación ya por relieve, pero manteniendo el sentido completo de la secuencia lingüística. Pongamos algunos ejemplos de esta estructura:

(1) "Covid-19: diferencia entre casos positivos y casos diagnosticados" [TS42]

(2) "El peor día del Covid-19: ocho muertos en Ávila" [TS39]

(3) "El primer contagiado de Covid-19 que se sale de la UCl: 'Sois cojonudos, no tengo otra palabra"' [TS37]

(4) "Mediana de Voltoya: también los pueblos pequeños luchan contra la Covid-19" [TP17]

(5) "La residencia de mayores de Mombeltrán, libre de Covid-19" [TP05]

En los ejemplos (1) y (2) se aísla un elemento tematizador por medio del empleo de la marcación gráfica de los dos puntos. También se localizan titulares en los que se sitian el sujeto léxico y el complemento directo de verbo omitido también por los dos puntos y con la optatividad de emplear las comillas (3 y 4 ).

Por elidir verbos copulativos, encontramos estructuras cuyos sujetos léxicos y atributos se hallan enfrentados, contrapuestos, ya que es de fácil recuperación 
La prensa digital en tiempos de la COVID-19: análisis lingüístico de los titulares publicados en ÁVILARED

comprensiva por el lector. Ejemplos como (5) son los que mejor vislumbran la función informativa de tema y rema.

El camino de la omisión de unidades lingüísticas del tipo de artículos, de nexos y de sustantivos, que se reconoce en el corpus de Nadal Palazón (2012), es inexistente en nuestro estudio. Solo se reconoce un caso de elisión preposicional, posiblemente, una errata por olvido dada la rapidez de la edición y publicación en la web del periódico. El titular al que nos referimos es:

(6) "Los populares piden al Gobierno autonomía para destinar el superávit la Covid-19" [TE05]

Es indiscutible la tendencia de los titulares periodísticos analógicos a la estructura unimembre (Alarcos, 1977; Nadal Palazón, 2012), rasgo también notorio en nuestro corpus, como los que reproducimos en la secuencia ejemplificativa siguiente:

(7) "El Alzheimer en los tiempos de Covid" [TM01]

(8) "Nuevo fallecimiento por Covid-19 en una jornada sin ningún positivo por PCR" [TS11]

(9) "Zonas de salud de Ávila con más y menos fallecimientos por la Covid-19" [TS19]

(10) "Decálogo para los propietarios de mascotas ante el Covid-19" [TS43]

(11) "233 muertes por el Covid-19 en la provincia de Ávila" [TP08]

(12) "Instrucciones sobre el tratamiento de residuos ante el Covid-19" [TP15]

Estas secuencias representan el más claro valor del titular, esto es, el de sintetizar la noticia, el de trasladar un acontecimiento concreto con brevedad y claridad (Grijelmo, $\left.2008^{16}\right)$.

Nadal Palazón (2012) afirma que es muy frecuente, sobre todo en periódicos mexicanos, iniciar el titular con un verbo explícito posiblemente por el ánimo del periodista por destacar los conceptos de mayor interés y orientar al público lector. En nuestro caso, no resulta extraño que nos encontremos con la presencia de estas formaciones hiperbáticas (13-15) por ser una recomendación común en los manuales de estilo periodístico digital con el fin de llamar la atención de los lectores (Narvaja de Arnoux, 2015, p. 145) y evitar que "se agote [su] paciencia o se aburra" (Fundéu, 2012, p.51-52):

(13) "Cierra sus puertas Naturávila a causa del Covid-19" [TP14]

(14) "Dona todos sus fondos para adquirir materiales en la lucha contra el Covid-19" [TP12]

(15) "Empieza a funcionar el Covid-auto en Ávila" [TS48]

Si bien los ejemplos anteriores referencian verbos en forma personal, también incluimos enunciados cuyos inicios son participios, porque, como afirma Grijelmo $\left(2008^{16}\right.$, p. 477), "[el empleo de esta forma es] una manera de comprimir la idea que deseamos llevar al titular" y no es un error incriminatorio como mal redactor (Grijelmo $\left(2008^{16}\right)$ : 
La prensa digital en tiempos de la COVID-19: análisis lingüístico de los titulares publicados en ÁVILARED

(16) "Desinfectada la sexta planta del Hospital de Sonsoles tras quedar sin pacientes Covid" [TS26]

(17) "Desmontada la carpa del Covid-auto" [TS08]

(18) "Convocado un funeral por las víctimas de la Covid-19" [TS09]

(19) "Convocadas ayudas a pequeñas empresas turísticas para paliar los efectos del impacto de la Covid-19" [TE01]

El fenómeno de la construcción impersonal en tercera persona del plural es muy poco frecuente en nuestro corpus sin observar ningún desvío a lo observado en el estudio de la prensa española (Nadal Palazón, 2012). Con ellas, el periodista adquiere la indeterminación propia de los sujetos desconocidos o que no interesa dar a conocer:

(20) "Animan a las donaciones de órganos tras constatar un descenso del $85 \%$ de donaciones por la Covid-19" [TS10]

(21) "Crean los equipos 'Covid residencias' para acudir a las residencias de mayores" [TS50]

Muy relacionado con la impersonalidad se halla un empleo del tiempo verbal condicional, pues como sostiene los estudios gramaticales es una marca de discurso indirecto no atribuido a nadie. Este valor justifica la multitud de términos empleados para referirse a él: "de cita", "de estilo indirecto", "de conjetura" o "de rumor" —por el que hemos optado-. No obstante, "no hace ningún bien al periodista que [lo] usa, puesto que transmiten inseguridad, rumores. Más aún debemos expresar esta censura en lo que se refiere a los titulares" (Grijelmo, 2008 ${ }^{16}$, p. 474).

(22) "La Escuela Nacional de Policía podría acoger a 132 contagiados del Covid-19" [TS40]

A diferencia de lo que suele pasar habitualmente con el empleo abusivo del lenguaje numérico, durante estos meses atrás las cifras han sido las protagonistas de las noticias de los telediarios y de la prensa escrita; y su aparición en los titulares, como espacio aglutinador de información relevante, es más que necesaria. Este rasgo, que puede ser optativo en otras circunstancias, en la primera ola de COVID-19 en España ha resultado ser prescriptivo por la necesidad diaria del ciudadano por estar informado del devenir de la pandemia en el país o de las consecuencias sufridas por una parte de la población debido a la COVID-19. En este sentido, localizamos indistintamente rótulos con números representados mediante cifras (23-26) o con palabras - denominadas "numerales"- (27-28) o hibridación de las dos maneras anteriores (29). Ahora bien, la codificación de datos numéricos en la escritura está sujeta al criterio general de preferir el empleo de cifras en titulares por su concisión y claridad, pero si se opta por la palabra "no es recomendable mezclar en un mismo enunciado números escritos con cifras y números escritos con palabras" (RAE y ASALE, 2019, p. 500):

(23) "Sanidad cifra en 209 las muertes vinculadas al Covid en la provincia de Ávila" [TS20]

(24) "Más de 140 enfermos de Parkinson se quedan sin rehabilitación a causa de la Covid-19" [TS33]

(25) "Los diagnosticados por Covid-19 superan en Ávila las 2500" [TS36]

(26) "El Covid-19 ha contagiado a 51 sanitarios en Ávila" [TS46] 
La prensa digital en tiempos de la COVID-19: análisis lingüístico de los titulares publicados en ÁVILARED

(27) "El peor día de Covid-19: ocho muertos en Ávila" [TS39]

(28) "Dos nuevos muertos en Ávila elevan a nueva las víctimas mortales por el Covid-19" [TS49]

(29) "En dos días fallecen ocho mayores de residencia con Covid-19 y otros 20 con síntomas" [TS34]

\section{RESULTADOS}

De los 90 títulos analizados, $26(28.88 \%)$ responden tanto a las construcciones enunciativas de orden canónico (sujeto + verbo + complementos verbales) como a las que no contemplan ningún mecanismo de los anteriormente reseñados. En este sentido, se acercan a las normas de estilo para la titulación periodística, son informativamente completas y facilitan la rápida comprensión de la noticia.

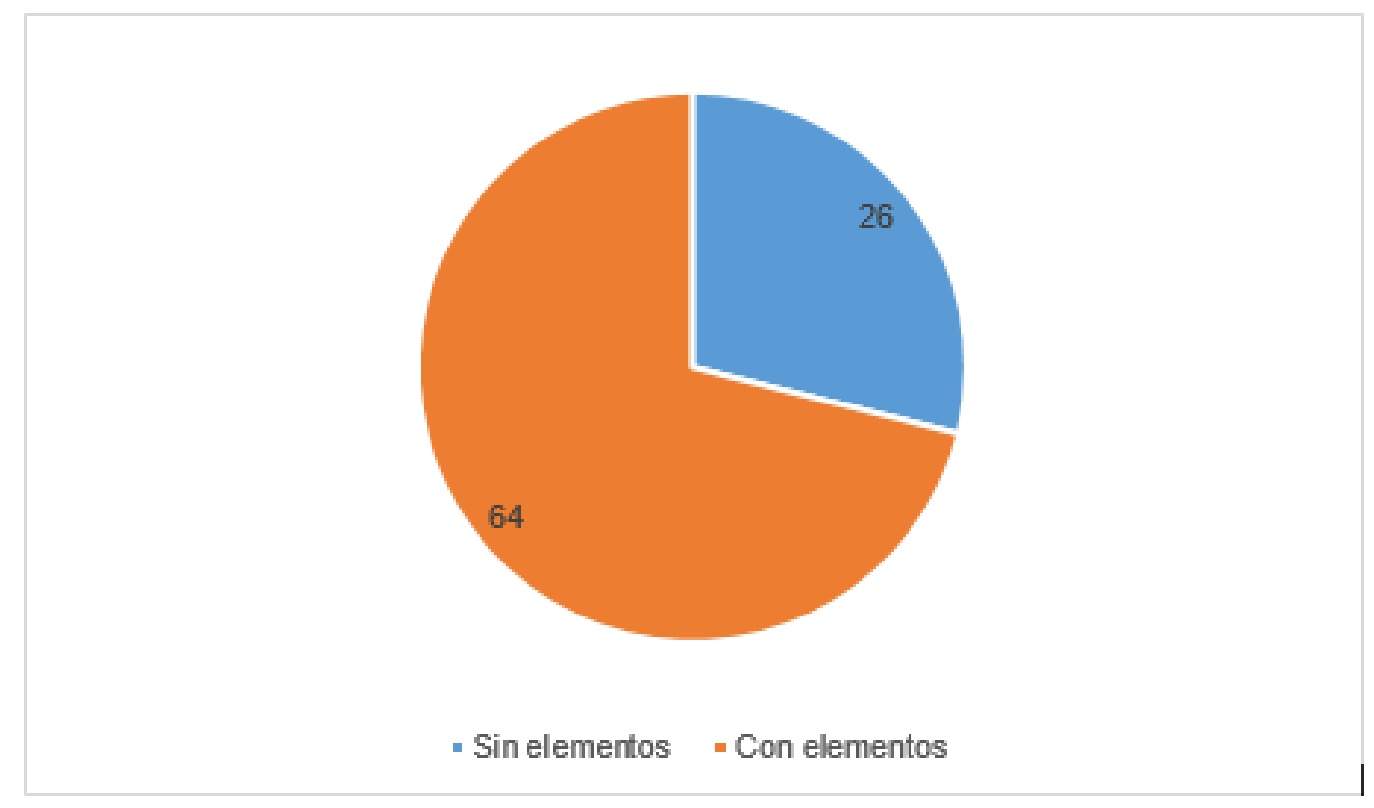

Gráfico 2. Contraste entre los titulares que contienen algún rasgo formal y los que no.

Fuente: Elaboración propia.

Dentro del grupo con rasgos de análisis, cuantificamos que solo 9 titulares se caracterizan por estructuras bimembres; 10 contienen elisión de verbos ya dicendi ya copulativos sin apreciarse omisión de otras categorías gramaticales como suelen ser habituales en titulares de prensa en papel. Enunciados con grado de impersonalidad tanto por la entidad inespecífica de la acción verbal como por el valor de conjetura del tiempo verbal del condicional son apenas inexistentes, al alcanzar el número de 6 apariciones en total.

Superior a 10 recurrencias se contabilizan los rasgos lingüísticos promotores de la expresión clara, breve e informativa de la práctica periodística digital: la estructura nominal, el inicio con verbo (ya conjugado ya en su forma no personal en participio) y la especificidad de expresión numérica.

Revista de Comunicación y Salud, 2020, Vol. 10, oㅡ 2, pp. 385-396 
La prensa digital en tiempos de la COVID-19: análisis lingüístico de los titulares publicados en ÁVILARED

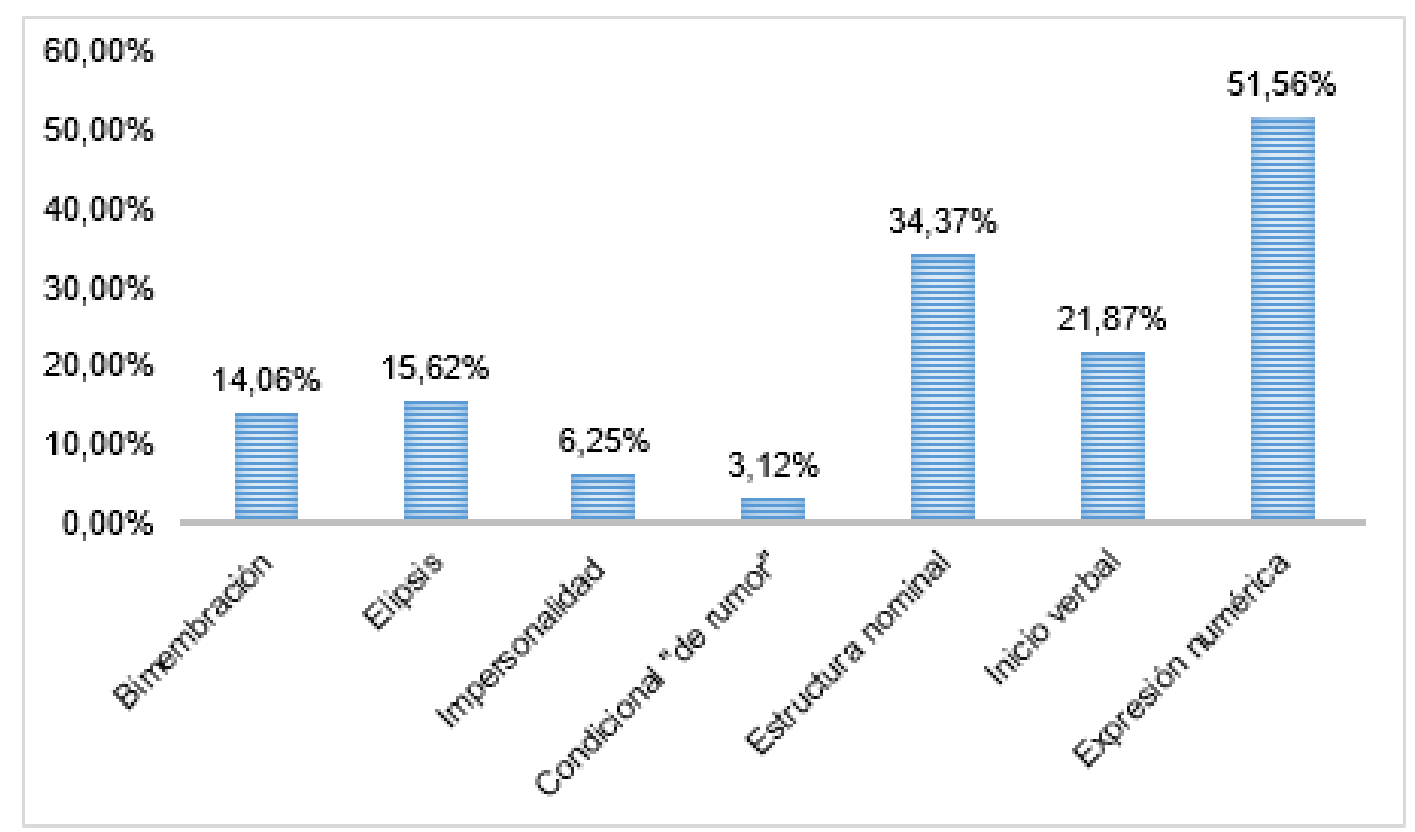

Gráfico 3. Porcentajes de los rasgos formales aparecidos en los 64 titulares.

Fuente: Elaboración propia.

\section{CONCLUSIONES}

A pesar de que los titulares son apenas una parte mínima del relato noticioso, este análisis sucinto ha permitido conocer la articulación formal de este tipo texto en la prensa digital de una ciudad de provincias durante los cuatro meses que duró el estado de alarma. Así, se puede validar la preferencia por enunciados sintácticamente completos y ordenados de manera canónica que resultan ser directos para el lector del siglo XXI.

Predominan los rótulos con enunciados numéricos, dada la situación de necesidad informativa que estaba viviendo el ciudadano español en aquel momento, y con estructuras nominales, elección correspondiente a un nivel de abstracción con la presentación de los eventos como situaciones estáticas. Asimismo, se destaca también como rasgo constante en nuestro corpus los titulares con inicio verbal. Estos tres elementos superan el $20 \%$ de recurrencia. En este sentido, su aparición confirma la recomendación práctica de los manuales de estilo periodístico digital: simplicidad, claridad y restricción de los juegos de sentido, en la medida de lo posible.

En cambio, a diferencia de la prensa en papel que está sujeta a la prescripción del espacio y las columnas y con ella la elaboración de titulares bimembres, con elipsis de distintas categorías gramaticales, escaso es el número de apariciones con rasgos formales notorios en un corpus de titulares sobre COVID-19. Por el tiempo donde la confusión reinaba en el espectador y/o lector, apenas ha habido cabida a estructuras de indeterminación y promotoras de rumorologías. No era (ni es) momento para ello. 
La prensa digital en tiempos de la COVID-19: análisis lingüístico de los titulares publicados en ÁVILARED

\section{REFERENCIAS}

Alarcos, E. (1977). Lenguaje de los titulares. En Lázaro Carreter, F. (Ed.) Lenguaje en periodismo escrito. Madrid: Fundación Juan March, 125-148.

Alcoba, S. (1983) El presente de los titulares de prensa: no deíctico, protiempo anafórico. Anàlisi: quaderns de comunicaciò i cultura, 7-8, 107-121. Recuperado de https://www.raco.cat/index.php/Analisi/article/view/41038

Cansino, G. (2003). La información de salud en los diarios de información general. En Catalán, José María \& Javier López Iglesias (Eds.) ¡Informáte en Salud” Los medios de comunicación y la información sanitaria. Madrid: Ediciones Eneida, 19-36.

Dijk, T. A. van (1990). La noticia como discurso. Comprensión, estructura y producción de la información. Barcelona: Paidós.

Fernández, S. (2016). Análisis lingüístico de la titulación periodística bajo un enfoque comunicativo: la recontextualizacion de la guerra de Irak en la prensa venezolana. Logos: Revista de Lingüística, Filosofía y Literatura, 26 (1), 82-101. doi: $\underline{10.15443 / R L 2606}$

Fogel, J.-F. y Patiño, B. (2007). La prensa sin Gutenberg: el periodismo en la era digital. Madrid: Punto de Lectura.

Francescutti, L. (2009). El tiempo de los titulares. Un análisis verbal de la titulación en la prensa española durante el periodo 1980/2005. Estudios sobre el mensaje periodístico, 15, 243-259. Recuperado de https://revistas.ucm.es/index.php/ESMP/article/view/ESMP0909110243A

Fundéu (Fundación del Español Urgente) (2012). Escribir en Internet: guía para los nuevos medios y las redes sociales. Barcelona: Galaxia Gutenberg.

Gallardo-Paúls, B. y Enguix Oliver, S. (2014). Estrategias de encuadre discursivo en el periodismo político: análisis de un corpus de titulares. Círculo de Lingüística Aplicada a la Comunicación, 58, 90-109. doi: 10.5209/rev CLAC.2014.v58.45471

Grijelmo, Á. $\left(2008^{16}\right)$. El estilo del periodista. Barcelona: Taurus.

Martínez Albertos, J. L. (1983) Curso general de redacción periodística. Madrid: Ediciones Paraninfo.

Nadal Palazón, J. (2012). Rasgos formales de los titulares periodísticos: notas sobre diez diarios del ámbito hispánico. Acta Poética, 33 (1), 173-195. doi: $\underline{10.19130 / i i f l . a p .2012 .1 .386}$

Narvaja de Arnoux, E. (2015). Los manuales de estilo periodísticos para las versiones on line: las representaciones del lector y su incidencia en la regulación de discursos y prácticas. Circula: reveu d'idéologies linguistiques, 2, 138-160. doi: $\underline{10.17118 / 11143 / 7981}$ 
La prensa digital en tiempos de la COVID-19: análisis lingüístico de los titulares publicados en ÁVILARED

Real Academia Española y Asociación de Academias de la Lengua Española (en línea). Diccionario de la lengua española. https://dle.rae.es/

Real Academia Española y Asociación de Academias de la Lengua Española (2019). Gramática y ortografía básicas de la lengua española. Barcelona: Espasa.

Rebollo Torío, M. Á. (2008). Análisis de los titulares en la prensa hispana. Anuario de Estudios Filológicos, 31, 163-175. Recuperado de https://dialnet.unirioja.es/descarga/articulo/2882946.pdf

Ruiz Acosta, M. J. (1992). Los titulares en Prensa: estudios de su evolución y lenguaje. En Antona, A. et al. (Eds.) Lenguaje informativo y filmográfico. Sevilla: Universidad de Sevilla. 77-84.

Soria Cáceres, C. H. (2017) Información ferroviaria de alta velocidad en España: estudio temporal de titulares de prensa en el diario 'El País'. Estudios sobre el mensaje periodístico, 23, 2, 1403-1417. doi: 10.5209/ESMP.58052

Zorrilla Barroso, J. M. (1996). El titular de la noticia. [tesis doctoral]. Universidad Complutense de Madrid, España.

\section{AUTORES}

\section{Carmen Vanesa Álvarez-Rosa}

Doctora con mención europea por la Universidad de Salamanca y profesora en la misma institución. Es licenciada en Filología Hispánica y en Filología Portuguesa. Pertenece al Grupo de Investigación ILSE: Investigaciones histórico-lingüísticas y de las hablas vivas del Sureste español y miembro colaborador de la Institución Gran Duque de Alba.

vane@usal.es

Orcid ID: https://orcid.org/0000-0002-9694-0843

Google Scholar: https://scholar.google.com/citations?user=miUntWoAAAAJ

ResearchID: C-7800-2017

Academia.edu: https://usal.academia.edu/CVanesa\%C3\%81lvarezRosa

\section{Ángel Manuel Romero López}

Sanitario con casi 20 años de experiencia en el sector público de la sanidad castellanoleonesa. Ha colaborado con el Programa Interuniversitario de la Experiencia de la Universidad de Salamanca.

amromero@saludcastillayleon.es 